\title{
COM JULIO MENDIVÍL OUVI JURUPARY E PARIXARA EM VIENA
}

With Julio Mendivíl I heard Jurupary and Parixara in Vienna

Con Julio Mendivíl escuché Jurupary e Parixara en Viena

Agenor Cavalcanti de Vasconcelos Neto ${ }^{1}$

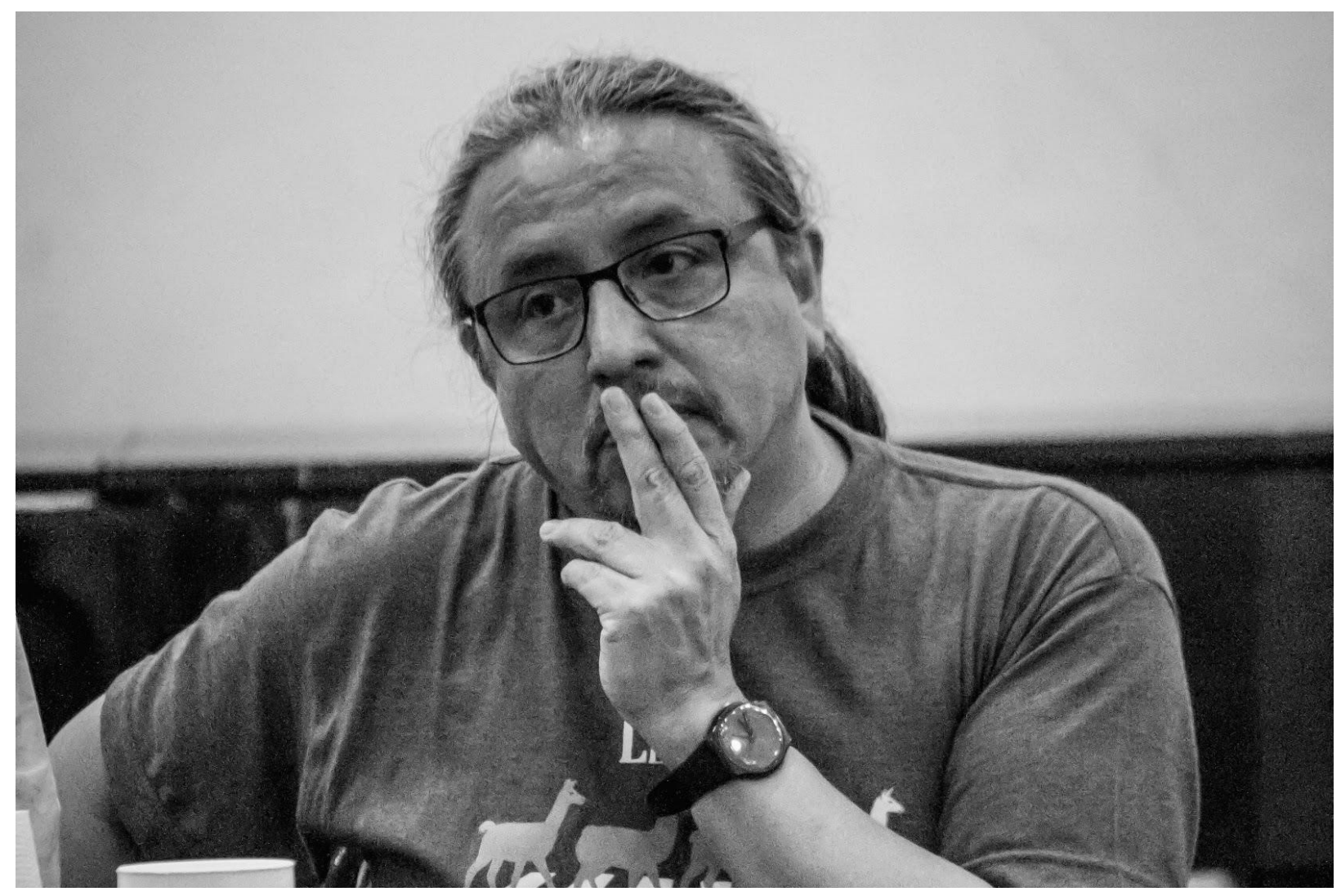

Foto: Ricardo Gonzáles 
Conheci o prof. Julio Mendivíl em um congresso sobre etnomusicologia que ocorreu em Madri, na Espanha, em 2016. Estava indo apresentar meu trabalho de pesquisa sobre música kuximawara - música indígena do Alto Rio Negro. Prof. Julio estava presente em minha sala de trabalho. Ao término de minha apresentação, alguém perguntou em espanhol, em um tom pessimista, o que, afinal, a música kuximawara possuía de indígena. Julio pediu para comentar e tentou fortalecer minha tese, explicando que estava claro que os interlocutores e o contexto cultural eram indígenas.

Quando o ouvi pela primeira vez em 2016, não imaginei que faria doutorado sanduíche com sua orientação. Em Viena, no inverno entre 2018 e 2019, pude conhecer melhor o professor, pesquisador e pessoa incrível que é Julio Mendivíl. Ele nasceu no Peru e foi para a Europa jovem. Na Alemanha, deu aulas em diversas instituições renomadas. Em 2018, foi convidado a assumir uma vaga de Etnomusicologia da Universidade de Viena.

Lá, por seis meses, pude presenciar uma das mais sensacionais cenas que o mundo acadêmico pode proporcionar. Eu ouvi o Parixara em Viena. Em uma aula de Introdução à Etnomusicologia, vi todo conteúdo que eu estudava há anos sobre música indígena produzido por Koch-Grünberg ser utilizado em uma sala de aula. O trabalho desenvolvido por Julio é referência na área. Dominando o espanhol, o inglês, o alemão e o português, é convidado para diversos congressos e eventos sobre a disciplina.

\section{Entrevista com Julio Mendivíl}

Agenor Vasconcelos Neto: Você poderia fazer um breve resumo de sua trajetória? Dos motivos e circunstâncias que te levaram do Peru à Viena. Em quais universidades você trabalhou?

Julio Mendivíl: Bueno, yo tuve la suerte de trabajar desde muy joven con Chalena Vásquez, que fue una de las más destacadas musicólogas peruanas. Ella me contrató como asistente de investigación y así me quedé fascinado con la etnomusicología. Como al mismo tiempo realizaba actividades como músico, me ofrecieron viajar a Europa en una gira y así llegué a Alemania. Cuando me enteré que, a diferencia del Perú, en Alemania sí existía la carrera de etnomusicología, me inscribí en la Universidad de Colonia y comencé a estudiar con Rüdiger Schumacher, especialista en música gamelán de Java. Ahí hice el grado y el doctorado y también la habilitación que es como un segundo doctorado que se exige Alemania para ser titular de cátedra. He tenido la suerte de dirigir en Alemania la cátedra de etnomusicología en la Universidad de Colonia como suplente y luego fui director del Center for World Music de la Universidad de Hildesheim. En Frankfurt fui titular de cátedra en etnomusicología y el 2017 decidí dejar Alemania para asumir la cátedra de etnomusicología en Viena, donde trabajo actualmente.

A. V. N.: Como se relaciona na sua obra os estudos sobre gênero e etnomusicologia?

J. M.: Bueno, la música está muy relacionada a las identidades de género. Todas las culturas producen y reproducen concepciones de género a través de la música. En las prácticas musicales encontramos modelos de comportamiento para hombres y mujeres o formas de interpelarlos; los mismos instrumentos musicales suelen tener connotaciones de género, entonces en mi obra lo único que he hecho es, como otras colegas, prestar atención a estos vínculos entre música e identidades de género. Últimamente me he dedicado al estudio de la violencia de género en el campo de la música. Ahí trato de usar una visión más interseccional y combinar cuestiones de género con cuestiones de clase y con la imaginación racial de nuestros pueblos. 
A. V. N.: Segundo seus estudos nessa linha, há dados que demonstram a existência de construções de gênero nos trabalhos musicológicos sobre a música dos Andes. Como isso se dá exatamente?

J. M.: Bueno, no solamente los músicos y las músicas tienen identidades de género, también las musicólogas y los musicólogos. Asimismo nosotros como investigadores estamos imbuidos de ideologías de género sobre lo que es masculino o femenino. En el caso de la música de los Andes, esta es descrita a principios del siglo XX como una música mujeril con lo cual se quería expresar que era una música fundamentalmente melódica, simple, débil y poco abstracta en comparación con la música decimonónica. Este menosprecio va a llevar a una generación de estudiosos posterior a plantear una visión contraria que ponía la música andina como exageradamente viril, como una música guerrera. ¿Cómo es esto posible? Suzanne Cusick y Fred Maus ya han demostrado en la musicología estadounidense que nosotros los investigadores también construimos subjetividades a través de los textos que escribimos. Yo encuentro lo demuestro también en el caso de la musicología sobre los Andes. Ahora, debo decir que no fueron estos textos los que me llevaron a "descubrir" las construcciones de género en los textos musicológicos sobre la música de los Andes, sino al revés, al leer la musicología sobre los Andes el lenguaje de los investigadores era tan abiertamente sexualizado y reproducía tantos estereotipos de género que comencé a buscar literatura al respecto.

A. V. N.: Com esse texto (Cosa de hombres: sobre construcciones de género en la musicología sobre la música de los Andes), você ganhou o prêmio internacional de etnomusicologia "Otto Mayer-Serra Award" da Universidade de Riverside Califórnia. Qual a importância de prêmios e incentivos como esse para sua obra?

J. M.: Creo que los premios siempre son un incentivo para investigadores, para potenciar la obra de gente que se está posicionando en el campo de la academia. En mi caso, yo había ganado con anterioridad el Premio Samuel Claro Valdés el 2012 y luego el Otto Mayer-Serra. Creo que esos premios me dieron visibilidad y me ayudaron a tener más presencia en América Latina.

A. V. N.: De modo geral, qual a relação que o Schlager possui com o nacionalismo alemão? Há uma aproximação do fascismo e regimes totalitários com a música popular? Em que sentido?

J. M.: Mucha gente supone una relación directa entre nacionalismo y schlager, pero la verdad es que dicha relación es muy débil. En cambio el schlager está estrechamente relacionado con el concepto de heimat, que se podría traducir como "terruño". A diferencia del nacionalismo, la identificación no es con la patria sino con la patria chica, con el lugar donde uno nació y creció, es decir, un espacio privado y no colectivo. Además se trata de una lugar idílico, que por lo común no corresponde con la realidad.

A. V. N.: Você já morou no Brasil e realizou um trabalho de pesquisa sobre a música sertaneja. Qual o período e cidade que você viveu aqui?

J. M.: Viví el 2003 y el 2004 en Brasil, muy cerca de São Paulo. Como vivía en el interior, me dediqué a recolectar datos sobre la música que me rodeaba. Yo había pensado que terminaría estudiando el samba o las batucadas brasileñas, pero lo que la gente oía ahí donde yo vivía era la música sertaneja. Yo no iría tan lejos como para decir que hice una investigación sobre la música sertaneja. Me interesó el tema y junté algunos datos, por lo que publiqué algunos artículos, pero jamás realicé un estudio a gran escala. Por lo demás, siempre estoy leyendo sobre Brasil, sobre todo sobre la música indígena brasileña, que me interesa mucho. 
A. V. N.: Você poderia nos descrever brevemente como foi a sua experiência trabalhando em uma grande gravadora, como a EMI Deutschland? Esse trabalho contribuiu para o desenvolvimento de seu trabalho acadêmico?

J. M.: Llegué a EMI Germany gracias a mi amigo y colega Oliver Seibt. Él tenía un trabajo como auxiliar estudiantil y me recomendó. Trabajé varios años en lo que era estudio de mercado y en algunas oportunidades como asesor de artistas de artistas de schlager. Sí, yo diría que esa experiencia sí influyó en mi carrera etnomusicológica. En los estudios de música popular la industria musical suele ser satanizada y mi experiencia en EMI me mostró que esa satanización en gran parte se basaba sobre prejuicios. La mayoría de gente que describe a la industria de la música como algo meramente capitalista y comercial, no conoce bien el funcionamiento de dicha industria y por eso generaliza de una manera irresponsable. La industria musical no es una entidad homogénea y mucho menos un campo social sin competencias internas. Es un mundo muy complejo que merece una mirada más profunda que la que permiten los prejuicios.

A. V. N.: No intercâmbio que realizei em Viena sob a sua orientação, semestre de inverno de 2018, cursei a disciplina "Introdução à Etnomusicologia". Lembro que você abordou o surgimento da antropologia, da "observação participante" e de vários outros métodos que a disciplina desenvolveu para organizar os dados e interlocuções do trabalho de campo. Você concorda que etnomusicologia é também antropologia da música? Por quê?

J. M.: Bueno, seamos sinceros, hay varias etnomusicologías. La que yo profeso es una basada en métodos etnográficos y en un posicionamiento relativista cultural. Cuando uno ve la herencia cultural que ha forjado la musicología, uno se encuentra con una realidad muy normativa que no habla de genios, de grandes obras, de cánones. La etnomusicología, como la antropología social, pretende una mirada no valorativa de las prácticas musicales. Además de eso, la forma de investigación que usamos se basa en los métodos antropológicos como el trabajo de campo, la observación participante, las entrevistas, etc.. Entonces, para mí la etnomusicología es una antropología de la música, una musicología que no quiere discernir qué es bueno y qué es malo, sino que pretende entender las culturas musicales desde su lógica interna. Es decir, a mi criterio la etnomusicología es una etnología musical.

A. V. N.: No contexto acadêmico da Universidade de Viena, a etnografia é entendida como método para a disciplina Etnomusicologia?

J. M.: Cuando llegué a Viena, todavía había aquí existía una tradición muy cercana a la musicología comparada que trataba de hacer una cartografía de la música a nivel mundial. Las colegas veían la etnomusicología como una disciplina musicológica. Desde mi llegada, el instituto se ha orientado más hacia la antropología de la música y al estudio de la música como fenómeno social y nos ocupamos además de temas con relevancia política como la música y la violencia, la música y la protesta social o la música y poscolonialismo.

A. V. N.: Nessas aulas, lembro que um aluno ou aluna, não recordo ao certo, perguntou se poderia ir ao trabalho de campo sem ler nenhuma bibliografia para ter suas "próprias e verdadeiras" impressões sobre o campo. Qual a importância de uma boa revisão bibliográfica para um bom trabalho de campo?

J. M.: Hay algunos colegas como Gerhard Kubik, que piensan que lo mejor es ir al campo sin hipótesis de trabajo previas. Es una posición que se encuentra mucho en quienes trabajan con la grounded 
theory. Uno va al campo y recién allí formula hipótesis según los datos recopilados. Pero esto no debe confundirse con ir al campo sin haberse preparado adecuadamente. Nuestras colaboradoras esperan de nosotros una preparación en los temas que queremos tratar, si no es el caso, entonces los informantes o colaboradores pierden el interés en hablar con nosotros, pues nos ven como ineptos. Eso quiere decir que una de las tareas del investigador o la investigadora es leer la bibliografía existente sobre el grupo humano que le interesa, de manera que en el campo no tenga que empezar de cero. El trabajo bibliográfico antes del trabajo de campo es fundamental para la realización de una buena etnografía musical.

A. V. N.: De maneira geral, sua tese de mestrado mostra por meio de antigas pinturas e outros dados o uso da flauta de cervídeo entre os povos andinos. Hoje em dia fora de uso nos Andes, a flauta está presente nos povos indígenas amazônicos, especialmente entre Brasil-Venezuela-Colômbia. O que seus estudos apontaram sobre essa flauta?

J. M.: En mi estudio, por primera vez se compararon las diferentes tradiciones de flautas de cráneo de cérvido en América del sur. Gracias a esas comparaciones pude mostrar que tanto en los Andes como en la amazonia las flautas siempre aparecen vinculadas a ritos sobre la fertilidad, representados a través de danzas de venados. Igualmente pude mostrar los vínculos con las tradiciones de flautas de pan (carrizo o carriço) y su inmersión en contextos religiosos más grandes todavía. Observar el proceso de extinción en Colombia igualmente me permitió desarrollar hipótesis sobre el proceso de extinción en tiempos coloniales y sugerir que lo que desestabilizó la tradición de las flautas no fue solamente la persecución que sufrió por parte de los españoles, sino también la desestructuración del sistema religioso en el cual las flautas estaban vigentes.

A. V. N.: A partir dessa flauta, como você pensa essa relação dos povos dos Andes-Amazônia se tratando de música? O que ela nos diz sobre uma possível conexão Andes-Amazônia?

J. M.: En verdad, las flautas vienen a corroborar lo que muchas fuentes ya venían mostrando: que el intercambio musical entre las culturas andinas y amazónicas ya en tiempos prehispánicos era muy intenso. Mucho tiempo se pensó que este intercambio fue mínimo debido a que la Amazonia no fue conquistada militarmente por los incas, pero la arqueología viene demostrando que sí hubo influencias mutuas. Un aspecto importante de mi investigación fue quizás entender que estos procesos como dialécticos nos permite romper con la cuestión del origen - o sea si las flautas partieron de los Andes hacia la Amazonia o de la Amazonia a los Andes- y concentrarnos en el estudio de la cultura como fenómeno móvil y cambiante.

Recebido em 23/11/2020

Aceito em 11/12 /2020 
